or outer, twilight, extending in reality to far beyond and above the place of the said cloudlets, was on this occasion painted, or blocked, out by dark dun colour. Nearly half the heavens were so obscured, and the earth below was as dark. No wonder then that the residual strip of untouched twilight shone so conspicuously in contrast.

But what is that darkness below an auroral arc?

It has been compared to the dark space under the negative pole of a highly rarefied gas-tube, when an electric spark is passed through it. And if we add in idea that it extends downwards to a certain angular distance from the sun, say $20^{\circ}$, and keeps to that, - the suggestion may explain why the silverblue cloudlets were seen higher over the northern horizon in the end of June and beginning of July, than at the end of the latter month; and also why they are never seen in the winter. But a still greater instrumental curiosity manifested itself in this, that the bright auroral citron-coloured line was also given in the spectroscope out of every part of that large expanse of auroral shade; and almost, though not quite, as well as from the bright track along its outer and upper edge ; just as if, however dark to the unassisted eye, the black-brown space was yet somewhat luminiferous to the peculiar power of the prism.

On the next night after this interesting midnight experience, there was no aurora, and the twilight extended faintly to many degrees higher than the position of the blue clouds of the previous night, and in fact spread into and over the region which was before so decidedly "aurora blackened."

But the next night after that again, viz. two nights after the display, there was a wet drizzling mist which continued through the early hours until more than a quarter of an inch of rainfall had been gathered. Admirably confirming therefore the late Sir Robert Christison's often strongly expressed opinion that 48 hours after a great aurora, abundant rain is sure to follow,an opinion too which I have only just heard was formed quite independently in Canada by my friend Mr. R. S. Haliburton, who is even now introducing it into his theory of "the aqueous origin of the aurora," so far as that can be carried; but without explaining either the citron line in the spectrum; or the effect on the magnetic needle.

15, Royal Terrace, Edinburgh, July 31

\section{The Bright Clouds}

THE bright cirrus-like clouds are very common here this summer. I have seen them here on the nights of the I2th, I 8th, 2oth, and 24th of last month, and on the rst inst., also at Gilsland on the 27th ult., in fact I do not know that in the last fortnight there has been a single night on which the northern sky has been quite free from lower clouds on which they have not appeared more or less ; sometimes, however, they appear but for a short time, and in a very limited area of the sky. I have tried to keep a watch to see them in the day-time, but have not succeeded as yet; the nearest approach to success was on the 2oth ult., when I saw them as early as 9.22 p.m., at which time they were visible over the greater part of the sky, but in the south-east were not strikingly bright.

There is one peculiarity with respect to them that I have not seen mentioned in NATURE, and that is their motion; on the above dates, except the 20 th, I took notice of this, and in every instance the motion was from a northerly or easterly direction, whereas I have not noticed any ordinary cirrus moving from that quarter lately. Last night at from Io to $10.1_{5}$, when there were smail patches of these curious clouds, there was also at the same time a great deal of ordinary cirrus moving from the west. This circumstance appears to indicate that there is quite a different current of wind in the upper atmosphere from that blowing at the lower elevation of ordinary cirrus.

I have no hesitation in saying that these extraordinary clouds do not shine with their own light, but with the direct light of the sun.

Sunderland, August 2

T. W. BACKHOUSE

\section{Aurora}

THE following is a record of aurora observed on July 27 at Ramelton, co. Donegal :-

9.30 p.m.-From west to east there were occasional pencils of reddish lights shooting up, while from east to west there were continuous pencils of yellowish and reddish lights, with intermittent clouds and columns of reddish light, rising between the north-east and north-north-west. The pencils were very steady, but increasing and decreasing in length, at times assisted by the clouds of red forming a corona at the zenith round the star Capella (?), at such times as pencils shot up from the southward, on a rude irregular cross. The corona and cross appeared and disappeared quite rapidly. The clouds and columns of reddish light were succeeded by flashes and pencils of bright silver light, they being most frequent and brilliant between the north and west, the flashes being sometimes in long narrow wavy clouds that rapidly ascended, or narrow sheets that appeared and disappeared nearly instantaneously. They became more and more brilliant, especially to the north-north-west, till the display was greatest between 10.30 and 10.45 .

10.45 p.m.-About this hour the continuous pencils of yellow and reddish lights between the east and west disappeared with the other light 3 , but about five minutes afterwards, to the northward, silver pencils and sheets appeared, veering from thence gradually towards the north-east and east. Some of the sheets hung at times in clouds that formed small arcs, that slowly rose obliquely, and moving eastward till about II o'clock, when all the lights disappeared, except that at long intervals faint pencils or flashes might shoot up on a small arc of silver clouds; but at II.25 there was another brilliant display. First there appeared an arch of silver light, i+s centre being about northnorth-west, then two arches that began sending up horns and pencils of light. The upper arch was a little below the North Star, while the lower one went through the Pointers of the Plough; these two arches were succeeded by one at II.35. The crown of the arch was very unsteady, moving from north to north-northwest and back again, its shape and the accompanying horns and pencils continually changing, the most brilliant and highest pencils being those that shot up to the north-westward. This display continued more or less brilliant till 11.45 , when clouds came un and prevented further observations; but at midnight the position of an arch was distinctly defined behind the clouds. At I a.m. the clouds had cleared away and no lights were vi-ible. The night was not favourable for seeing an aurora, as it was very light and clear, yet at times the lights were very brilliant. Although the arches were of the same class of silver light as those seen from the North Atlantic or the Canadian Lakes, yet they were not steady like those, as they were continually shifting their positions or disappearing and reappearing. During the previous day there was a northerly wind with at times intensely cold squalls of misty rain.

\section{G. H. KinahaN}

Aвout II.I 5 p.m. July 27, I886, I observed an incipient stage of the aurora borealis, and about c.ro a.m. of the 28th a considerable display of auroral colour commenced; but between $0.30 \mathrm{a} . \mathrm{m}$. and $\mathrm{I}$ there was a vivid display of huge auroral sheets and columns; indeed, it did not require much to entitle the golden scene to the epithet-magnificent. There was a prismatic arc, not unlike a rainbow, which spanned from the northwest to the east, and measured about $70^{\circ}$ from its centre to the horizon. All under this arc was a flood of white light, which the aurora did not in the least degree invade. From this arc developed a brilliant aurora borealis to a few degrees south of the zenith; and, with other constellations, Cygnus, Lyra, and the Northern Crown were overwhelmed in a golden flood. In this part of our northern latitude there are at present highly favourable conditions for phenomenal refraction of solar light. On the morning of the 27th and 28 th the earth-shine on the moon was very bright, and I have no doubt but that these atmospheric conditions are also favourable to auroral displays. Every vestige of the aurora borealis disappeared about 2.30

I do not think that an aurora as early as July is on record; in the Culloden meteorological records there is not one recorded so early as July from 1841 to $18 \% 0$; indeed August is reckoned unusually early for an aurora borealis. I recollect a most magnificent one about the beginning of August in 1882, in the upper reaches of Lanarkshire; the huge vivid sheets and columns reached from the west all along the horizon to the east, and up the vault of heaven to the zenith, and with their fleet shifting flashes and bursts of prismatic coruscations, they lighted up the earth with ineffable glory.

The Academy, 22, Argyll Street, Paisley, July 28 